\title{
Assess the Knowledge Regarding Janani Shishu Suraksha Karyakram among Antenatal Mothers Attending Antenatal Clinic at Selected PHC, Tamil Nadu
}

\author{
Kumudhavlli D ${ }^{1}$, Karthi $\mathbf{R}^{2}$, J Sofiya ${ }^{3}$, M Swetha ${ }^{4}$, V Subasri ${ }^{5}$, U Tamizhvani ${ }^{6}$, \\ M Surya $^{7}$, K Thavapriya ${ }^{8}$, P Suyambuselvi ${ }^{9}$, T Thilagavathi ${ }^{10}$ \\ ${ }^{1}$ Assistant Professor, Dept of Community Health Nursing, E.S College of Nursing, Tamilnadu \\ ${ }^{2}$ Professor \& HOD Dept of MSN, E.S College of Nursing, Tamilnadu \\ ${ }^{3-10}$ Final Year B.Sc., Nursing, E.S College of Nursing, Tamilnadu
}

Corresponding Author: Kumudhavlli D

\begin{abstract}
Aim: to assess the knowledge regarding Janani Shishu Suraksha Karyakram among antenatal mothers attending antenatal clinic at selected PHC in a view to develop an information booklet regarding Janani Shishu Suraksha Karyakram.
\end{abstract}

Objectives: (i) To assess the level of knowledge regarding Janani Shishu Suraksha Karyakram among antenatal mothers. (ii) To associate the significant between the level of knowledge regarding Janani Shishu Suraksha Karyakram among antenatal mothers with selected demographic variables.

Methods \& Material: A quantitative research approach .descriptive survey design with one group pretest design was adopted 50 samples were selected for the study by using non probability convenient sampling techniques.

Result: The finding shows that the level of knowledge majority of mother 37 [74\%] had moderate knowledge \& 6 [12\%] had adequate knowledge and 7 [14\%] had inadequate knowledge; there is association between level of Knowledge with the Demographic Variables like Religion and Education of Mothers and the is no association in Age, Occupation, Type of Family, family Income Per Month and No. of Gravida.

Conclusion: The findings of the study show that in level of knowledge, the mean value was 10.66 with the standard of 3.8859 . The study concluded that most of the antenatal mothers are having moderate knowledge regarding Janani
Shishu Suraksha Karyakram among antenatal mother.

Key Words: Antenatal Mothers, Janani Shishu Suraksha Karyakram

\section{INTRODUCTION}

Maternal and child health is one of the eight millennium development goals. Maternal and child mortality ratio and infants mortality rate strongly reflect the overall effectiveness of health system.

Improving the well-being of mothers, infants and children is an important public health goal for the United States. Their well -being determining the health of the next generation and can help predict future public health challenges for families, communities and the health care system. The objectives of the maternal, infants and child health topics areas address a wide range of condition, health behaviors and health system indicators that affect the health, wellness and qualities of life of women, children and families.

While there has been a decline in worldwide maternal mortality rates and infant mortality rates much more has to be done. High rates still exist particularly in impoverished communities with over $85 \%$ living in Africa and southern Asia. The effects of a mother's death result in vulnerable families and their infants. If they 
survive child birth are more likely to die before reaching their second birth day.

India has MMR of 167/1,00,000 and IMR of 40/1000 live birth in 2013, about 50,000 women in India died due to pregnancy related complication. Most of these deaths could be prevented through universalizing skilled care at birth and the round -the -clock emergency obstetric care [EMOC] through the public health systems.

Lack of liquid cash and round the clock availability of transport are two major stumbling blocks for institutional care of childhood birth three financial burden also plays a cervical role in accessing health care in general and maternity care in particular in resource -constrained settings.

A major proportion of health expenditure in India is met by households $(61.8 \%)$ followed by the government (28.2\%), business firms, and external flows. Often the health expenditure in India is Catastrophic for the resource -constrained households. Similar pictures are also noted for maternity care, especially in rural and slum areas. poor households often resorts to borrow cash or sell assets to meet the health expenditures.

According to recently released sample registration bulletin (SRS). India has registered a significant decline of 8\% in infant mortality rate (IMR) in 2016. Infant mortality rate in India has declined by three points from 37 per 1000 live birth in 2015 to 34 per 1000 live birth in2016 as per the latest government data released on 2019 that the infant mortality rate has declining by proper care

\section{IMR AND MMR:}

The WHO has commented India's progress in reducing maternal mortality ratio (MMR) by $77 \%$ in 1990 to 130per 1000live birth in 2016. This progress puts in India on track towards achieving sustainable development goal (SDG) target of MMR below to by 2030 MMR is below millennium development goal (MDG) target

State-subsided demand-side financing like JSSK has largely closed urban-rural divide traditionally seen in institutional births. JSSK also allow all pregnant women delivering in public health institutional free transport and no expenses delivery including cesarean section health status maintenance

Every year 13 lakes newborn die within one year of birth .213 of newborn death occur within 4 weeks. First 28 days are critical to save life of the child about 67,000 of women were dying every year due to pregnancy related complication about $42 \%$ of maternal mortality rate in 2015 . This are reduced by proper postnatal care and promoting the institutional deliveries in India. This may be enhanced by creating the awareness of the JSSK scheme-based knowledge in rural areas for decreasing the maternal and infant mortality rate.

As per the latest report (2016-2018) of sample registration released by Registration General of India (RGI), MMR of India per 100,000 live birth has declined to 113 in 2016-2018 from 122 in 2015-2017 and 130 in 2014-2016

Janani shuraksha yojana a demand promotion and conditional cash transfer scheme is implemented with the objective of reducing MMR and IMR by encouraging institutional deliveries.

Under Janani shishu shuraksha Karyakram, every pregnant woman is entitled to free delivery including caesarean section in public health institution.

Several initiatives have been launched by ministry of health and welfare including (JSY) which is one of the key interventions that has resulted in phenomenal growth in institutional deliveries. However during programme review the state and district programme officers high lightened the situation where at times there is paucity of essential logistic like drugs consumables, facilities of referral etc.

Such situation is often being exploited by unwarranted persons and the beneficiaries are subjected for in curing out of pocket expenses. Thus, in order to reduce out of pocket expenses under the overall 
umbrella of NRHM, Janani Shihu Suraksha Karyagram was launched on 1 June 2011 ensuring free entitlements like cashless delivery c-section and management of sick neonate up to 30 days.

The utilization of any scheme depends on the level of awareness, among beneficiary's despite of wide availability of the scheme, there is poor utilization of the JSSK entitlements either due to ignorance or due to incomplete erroneous information about their use and procurement.

The JSSK initiative entitles all pregnant women delivery in public health institution to absolutely free and no expense delivery including cesarean section.

The scheme aims to eliminate to benefit more than 12 million pregnant women who access government health facilities for their delivery. Moreover, it will motivate those who still choose to deliver at their homes to optimum for institutional deliveries.

All the state and UTS have initiated implementation of the scheme. Awareness has been high lightened by many as a key indicator of success in a range of performance. Awareness level among beneficiaries helps us to know the extent to which the programme serving the purpose at root level. It is important to generate regionbased evidence on the awareness of JSSK entitlements. There are very few studies regarding assessment of awareness of JSSK entitlements and there was not a single study was in Villupuram region. Keeping this in mind, this study was conducted to know the level of awareness about various entitlements of JSSK among pregnant women and to examine the association between different socio-demographic factors and awareness level.

\section{STATEMENT OF THE PROBLEM}

A study to assess the knowledge regarding Janani Shishu Suraksha Karyakram among antenatal mothers attending Antenatal clinic at selected PHC, Villupuram District.

\section{OBJECTIVES OF THE STUDY}

$>$ To assess the level of knowledge regarding Janani Shishu Suraksha Karyakaram among antenatal mothers.

$>$ To associate the significant between the level of knowledge regarding Janani Shishu Suraksha Karyakaram among antenatal mothers with selected demographic variables.

\section{ASSUMPTION}

> Antenatal mother may have inadequate knowledge regarding the Janani shishu suraksha karykram.

> Antenatal mothers may unaware about the institutional delivery

> Antenatal mothers may not aware about the benefits of Janani Shishu Suraksha Karyakaram.

\section{METHODS AND MATERIAL}

Quantitative research approach and descriptive research design was adopted for the study. 50 antenatal mothers were selected Non Probability Convenience sampling technique Data was collected by using Structured Knowledge Questionnaires. It consists of 30 knowledge questions related to general information about Janani Shishu Shuraksha Karyakaram.

\section{FREQUENCY AND PERCENTAGE DISTRIBUTION OF LEVEL OF KNOWLEDGE ON JSSK AMONG ANTENATAL MOTHER}

Table:4.2 frequency percentage distribution of level of
knowledge on janani shishu suraksha karyakaram among
antenatal mothers. N=50
\begin{tabular}{|l|l|l|l|}
\hline S.NO & $\begin{array}{l}\text { LEVEL OF } \\
\text { KOWLEDGE }\end{array}$ & FRQUENCY & PERCENTAGE \\
\hline 1. & $\begin{array}{l}\text { Adequate } \\
\text { knowledge. }\end{array}$ & 6 & $12 \%$ \\
\hline 2. & $\begin{array}{l}\text { Moderate } \\
\text { knowledge }\end{array}$ & 37 & $74 \%$ \\
\hline 3. & $\begin{array}{l}\text { Inadequate } \\
\text { knowledge }\end{array}$ & 7 & $14 \%$ \\
\hline
\end{tabular}

Table: 4.2 Shows the frequency percentage of level of knowledge of about $6(12 \%)$ belongs to adequate knowledge, $37(74 \%)$ belongs to moderate knowledge, $7(14 \%)$ belongs to inadequate knowledge among selected antenatal mothers. 
Kumudhavlli $D$ et.al. Assess the knowledge regarding janani shishu suraksha karyakram among antenatal mothers attending antenatal clinic at selected PHC, Tamil Nadu.

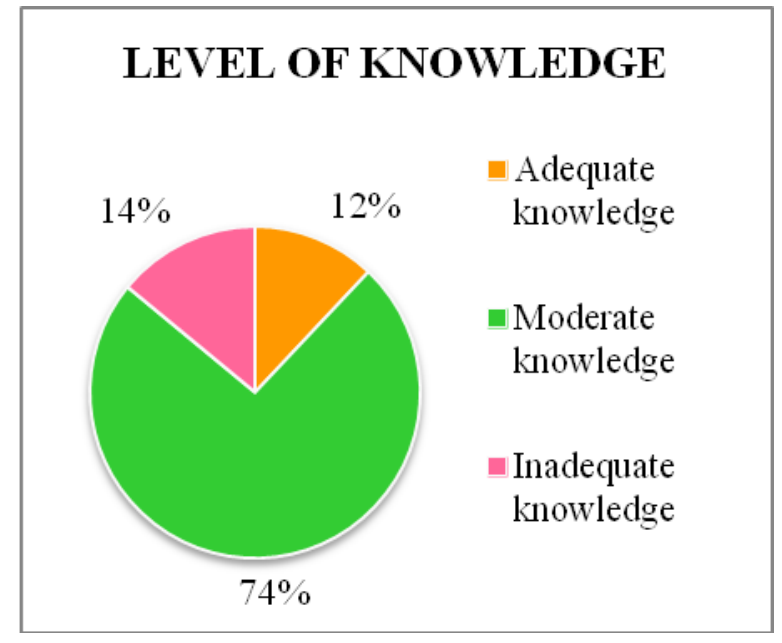

\section{ASSOCIATION BETWEEN THE LEVEL OF KNOWLEDGE AMONG ANTENATAL ON JSSK WITH SELECTED DEMOGRAPHIC VARIABLES}

Table:4.2 Association between the level of knowledge among antenatal mothers regarding Janani shishu suraksha karyakaram with selected demographic variables. $\mathrm{N}=\mathbf{5 0}$

\begin{tabular}{|c|c|c|c|c|c|c|}
\hline S.No & Demographic Variables & $\begin{array}{l}\text { Inadequate } \\
\text { Knowledge }\end{array}$ & $\begin{array}{l}\text { Moderate } \\
\text { Knowledge }\end{array}$ & $\begin{array}{l}\text { Adequate } \\
\text { Knowledge }\end{array}$ & $\chi^{2}$ & $\begin{array}{l}P \\
\text { Value }\end{array}$ \\
\hline \multirow[t]{4}{*}{1.} & AGE & & & & \multirow[t]{4}{*}{4.134} & \multirow{4}{*}{$\begin{array}{l}0.3882 \\
\text { NS }\end{array}$} \\
\hline & a. $11-25$ years & 3 & 17 & 1 & & \\
\hline & b. $26-35$ years & 4 & 19 & 4 & & \\
\hline & c. above 35 years & 0 & 1 & 1 & & \\
\hline \multirow[t]{4}{*}{2.} & RELIGION & & & & \multirow[t]{4}{*}{29.167} & \multirow{4}{*}{$\begin{array}{l}0.0001^{*} \\
\mathrm{~S}\end{array}$} \\
\hline & a. Hindu & 7 & 37 & 4 & & \\
\hline & b. Muslim & 0 & 0 & 0 & & \\
\hline & c. Christian & 0 & 0 & 2 & & \\
\hline \multirow[t]{5}{*}{3 . } & EDUCATION & & & & \multirow[t]{5}{*}{9.567} & \multirow{5}{*}{$\begin{array}{l}0.048^{*} \\
\mathrm{~S}\end{array}$} \\
\hline & a.No formal Education & 1 & 0 & 0 & & \\
\hline & b.Primary and High School & 3 & 6 & 2 & & \\
\hline & c.Higher Secondary & 3 & 26 & 1 & & \\
\hline & d. Graduate & 0 & 5 & 3 & & \\
\hline \multirow[t]{5}{*}{4.} & OCCUPATION & & & & \multirow[t]{5}{*}{2.3409} & \multirow{5}{*}{$\begin{array}{l}0.6733 \\
\text { NS }\end{array}$} \\
\hline & a. Housewife & 6 & 22 & 3 & & \\
\hline & b. Self Employee & 0 & 5 & 1 & & \\
\hline & c.Private Employee & 1 & 10 & 2 & & \\
\hline & d.Govt. Employee & 0 & 0 & 0 & & \\
\hline \multirow[t]{4}{*}{5.} & TYPE OF FAMILY & & & & \multirow[t]{4}{*}{1.6818} & \multirow{4}{*}{$\begin{array}{l}0.794 \\
\text { NS }\end{array}$} \\
\hline & a. Nuclear family & 1 & 10 & 1 & & \\
\hline & b. Joint family & 6 & 27 & 5 & & \\
\hline & c. Extended family & 0 & 0 & 01 & & \\
\hline \multirow[t]{4}{*}{6.} & $\begin{array}{lll}\text { FAMILY } & \text { INCOME } & \text { PER } \\
\text { MONTH } & & \\
\end{array}$ & & & & \multirow[t]{4}{*}{1.114} & \multirow[t]{4}{*}{$\begin{array}{l}0.819 \\
\text { NS }\end{array}$} \\
\hline & a. $<10000$ & 5 & 22 & 3 & & \\
\hline & b. $10,000-15,000$ & 2 & 14 & 1 & & \\
\hline & c. $>15,000$ & 0 & 1 & 2 & & \\
\hline \multirow[t]{3}{*}{7.} & NO. OF GRAVIDA & & & & \multirow[t]{3}{*}{3.682} & \multirow{3}{*}{$\begin{array}{l}0.4507 \\
\text { NS }\end{array}$} \\
\hline & a. Primi & 4 & 26 & 3 & & \\
\hline & b. Multi & 3 & 11 & 3 & & \\
\hline
\end{tabular}

Table 4.2: shows there is association between level of Knowledge with the Demographic Variables like Religion and Education of Mothers and the is no association in Age, Occupation, Type of Family, family Income Per Month and No. of Gravida.
DISCUSSION

The first objectives of the study is to assess the level of knowledge regarding janani shishu suraksha karyakram among antenatal mothers

The level of knowledge among 50 mothers $37(74 \%)$ had moderate knowledge 
Kumudhavlli $D$ et.al. Assess the knowledge regarding janani shishu suraksha karyakram among antenatal mothers attending antenatal clinic at selected PHC, Tamil Nadu.

and $6(12 \%)$ had adequate knowledge and $7(14 \%)$ had inadequate knowledge.

The second objectives of the study is to find the association the significant between the level of knowledge regarding the JSSK antenatal mothers with demographic variables

The finding of the study shows that there is association between level of Knowledge with the Demographic Variables like Religion and Education of Mothers and the is no association in Age, Occupation, Type of Family, family Income Per Month and No. of Gravida.

The finding of the study supported by the study Prasad at.al (2017), conducted a study on awareness regarding janani shishu suraksha karyakaram (JSSK) among mother a community-based cross-sectional study in rural area of Kaipur district, Chhattisgarh. Sample size 352 mother using multistage random sampling using predestined pretested performed chi-square test was applied to find out the association between awareness level and different socio-demographic variables $\mathrm{p}<0.05$ was considered significant, Among 352 mothers (58.80\%) maximum awareness (89.20\%) level of awareness Janani Shishu Suraksha Karyakram entailment for pregnant mothers and sick infants was found to be low extensive IEC needed to further. Increase the awareness regarding Janani Shishu Suraksha Karyakram entitlement to increase utilization among beneficiaries.

\section{CONCLUSION}

The findings of the study show that in level of knowledge, the mean value was 10.66 with the standard of 3.8859 . The study concluded that most of the antenatal mothers are having moderate knowledge regarding Janani Shishu Suraksha Karyakram among antenatal mother. Informational Booklet issued to all the Antenatal mothers regarding Janani Shishu Suraksha Karyakram.

Acknowledgement: None

\section{Conflict of Interest: None}

\section{Source of Funding: None}

\section{Ethical Approval: Approved}

\section{BIBLIOGRAPHY}

1. Chatterjee DS, chakraporty A, ghosh DP, das $\mathrm{D}$, singh $\mathrm{R}$, ghosh $\mathrm{P}$, awareness about Janani shishu suraksha karyakaram (JSSK) among pregnant mothers a community based study in a rural area of west Bengal India 2014-15 [9].1,5.

2. Park K. Preventive and social medicine, chapter 10 Preventive medicine in obstetrics, pediatrics and Gediatrics. Edition 20, Jabalpur 2009, PP447.B25.

3. Maternal Mortality Ratio bulletin (20112013) sample Registration system available from WWW. Census India gal. in.

4. Ministry of health and family welfare guidelines for Janani Shishu suraksha karyakram (JSSK) National rural health mission maternal health division government of India, nirmanbharan, New Delhi, June 2011.

5. Trends in child delivery at health facilities (institutional delivery) across India from 2008-9 to2012-13 community data gav.in.

6. Barot $\mathrm{DB} . \mathrm{AB}$, Implementation status of Janani Shishu Suraksha Karyakaram in Ahmedabad district, Int $\mathbf{J}$ Med Scl public health 2020,9(1),11-15.

7. Barva $\mathrm{k}$, barugh $\mathrm{R}$ ejah $\mathrm{J}$, saikia AM. Factors influencing the utilization of free delivery care under janani sishu suraksha karyakaram in kamrup district, assam india int $\mathrm{j}$ community hod public health 20173,166571 .

8. Mondal J,Mukhopadhyay DK, Mukhopadhyay S, Sinhababu A. Does Janai Shishu Suraksha Karyakram ensure costfree Institutional delivery A cross -sectional study in rural Bankura of west Bengal, India. Int J Curr Res Rev.2014;6;29-34.

9. Mitra S, halder D, sarkar AP siscoas D, sarkar GN evalvation of janani shishu saraksha karyakram in community development block of bankura district klest Bengal India a mixed methods approach Indian j community health 2016: 28.344-51.

10. Desphpande R. gadappa $S$, pagree $S$, dhaduti $\mathrm{R}$, andurkar $\mathrm{s}$, awarenees regarding janani shishu shuraksha karyakrama 
Kumudhavlli $D$ et.al. Assess the knowledge regarding janani shishu suraksha karyakram among antenatal mothers attending antenatal clinic at selected PHC, Tamil Nadu.

amoung pregnant women of marathcoaba Maharashtra India int $\mathrm{j}$ repord contracept obstet gynecol 2017,5:1985-91

11. Gupta MB gupta AK, mazta SR, a study on level of satisfaction among beneficiaries under janani shashu saraksha karyakram (JSSK) at regional hospital nahan (HP) into j sec sic 2016.5.55.

12. Mumbai international institute for population sciences and macro international; 2007 international institute for population sciences and macro international national family health survey(NFHS-3) 2005-06 India ip 2017
13. Tripathi N, Saini SK, Prinja S. Impact of Janani Shishu Suraksha Karyakram on outof-pocket expenditure among urban slum dwellers in Northern India. Indian Prdiatr. 2014;475-7.

How to cite this article: Kumudhavlli D, Karthi R, J Sofiya et.al. Assess the knowledge regarding Janani Shishu Suraksha Karyakram among antenatal mothers attending antenatal clinic at selected PHC, Tamil Nadu. Gal Int J Health Sci Res. 2021; 6(2): 7-12. DOI: https://doi.org/10.52403/gijhsr.20210402 